\title{
An experiment study on the impact mechanics properties of Cement Mortar affected by layer joints
}

\author{
WANG Jianguo ${ }^{1, a}$, YANG Yang ${ }^{2, b}$, YANG Jiqing ${ }^{1, c}$, LI Xianglong ${ }^{3, d}$, XU
}

\author{
Peiliang ${ }^{4, e}$ \\ ${ }^{1}$ College of Civil and Architectural Engineering, Yunnan Agricultural University, Kunming 650201, \\ Yunnan, China \\ ${ }^{2}$ College of Water Conservancy, Yunnan Agricultural University, Kunming 650201, China \\ ${ }^{3}$ Faculty of Land Resources Engineering, Kunming University of Science and Technology, Kunming \\ 650093, Yunnan, China \\ ${ }^{4}$ Datun tin ore, Yunnan Tin Co., Ltd, Gejiu 661000, Yunnan, China \\ awangjg0831@163.com, b1246064849@qq.com, c33478983@qq.com, dwangjg1987@126.com, \\ ebadtuoer@163.com
}

Keywords: Layer joints; cement mortar; Split Hopkinson Pressure Bar(SHPB); parallel cracks; impact speed

Abstract: With the help of SHPB apparatus, do the research on the energy transfer rule, strength characteristics and failure pattern of complete mortar testing piece and specimens with 1 3 joints, under the similar impact speed. In addition, regarding the double parallel cracks specimens as an example to explore how the impact speed regularly influenced the degree of damage of the specimens. Experimental results show that under the same incident energy condition, as the joint number increasing from 1 to 3 , the more joints, the heavier destruction of specimens which appear the pattern of multiple blocks. And there is a negative relationship between dynamic compressive strength and the number of joints testing pieces. The results of this study provide a reference for the analysis of the dynamic characteristics of laminated cement mortar material in construction engineering.

\section{Introduction}

The existence of joint stratification seriously influences the dynamic behavior of materials. As the most commonly used mortar material in all kinds of engineering, the number of layer joints on its dynamic properties is related to the quality and safety of engineering. In recent years, many scholars have done related work, Liu Hongyan ${ }^{]} \mathrm{al}^{[1-3]}$ has analyzed the relationship between the geometric features of joints and the dynamic failure characteristics of rock mass through mortar material simulation and SHPB impact test; Wang Jianguo and Yang Yang et al ${ }^{[4-6]}$ has used SHPB experimental device to study the influence of joint inclination, joint thickness, joint filling material and strain rate on dynamic mechanical properties of rock; Through model tests, Li Xinping et al ${ }^{[7]}$. has studied the propagation of stress wave in jointed rock mass under different in-situ stress and deduced the propagation equation of stress wave at multiple nonlinear joints under the influence of in-situ stress; Yuan Pu et al ${ }^{[8]}$ made use of the aluminum SHPB device to study the impact kinetics of lightweight foam concrete; Chai, $\mathrm{S} B$ et $\mathrm{al}^{[9]}$. has analyzed the propagation characteristics of stress waves traveling through biaxial parallel rock; Liu Tingting ${ }^{[10]}$, Yu $\operatorname{Jin}^{[11]}$ et al. have studied the law of stress wave propagation through rock joints and conducted energy analysis.

In order to make it more clear that the impact strength of layer joints on the energy transfer, energy dissipation, strength characteristics and failure mode of mortar materials, this paper will use 
the SHPB dynamic test device recommended by the International Society for Rock Mechanics Impact mechanical properties of the specimen to carry out research.

\section{Design of SHPB impact test}

\section{Preparation of Joint Mortar Specimens}

In order to study the influence of joint number on the dynamic characteristics of concrete materials, in the mortar specimens, they were made into one, two, three through-joints, respectively. The joint plane was perpendicular to the axial direction of the specimen, that is, the joint angle was $0^{\circ}$, specimen and joint design shown in Figure 1.
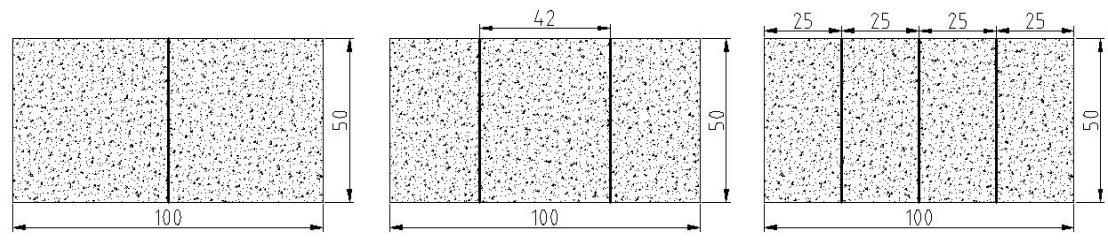

Fig. 1 Design drawing of specimens with different joint sets(Units: $\mathrm{mm}$ )

Through-joint production needed to use a small cutter installation with diamond blade (Figure 2) to cut on demand and Joint cracks with epoxy resin organic bonding, so that it could form a different number of joints mortar specimens, in addition, this study ignored the thickness and strength of epoxy resin. Forming the shape of the joint test piece shown in Figure 3, the physical and mechanical parameters of the mortar specimen measured by the XTR01 electronic pressure testing machine (as shown in Fig. 4) were shown in Table 1.

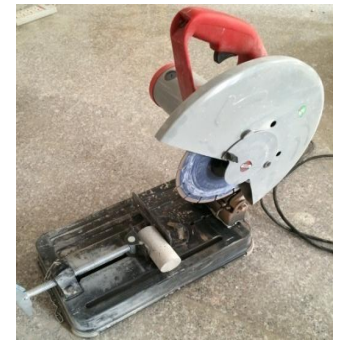

Fig. 2 Cut-off machine

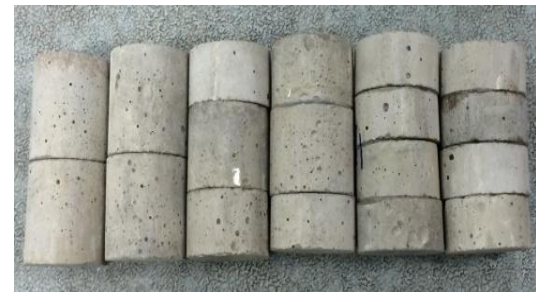

Fig. 3 Specimens with different joint numbers

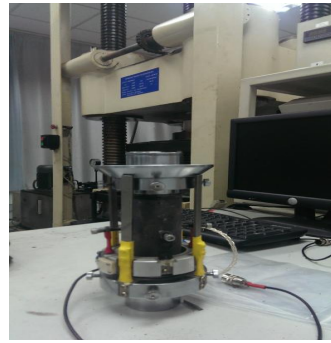

Fig.4 Press and stretch meter installation drawing

Tab. 1 The physical and mechanical parameters of simulated rock material

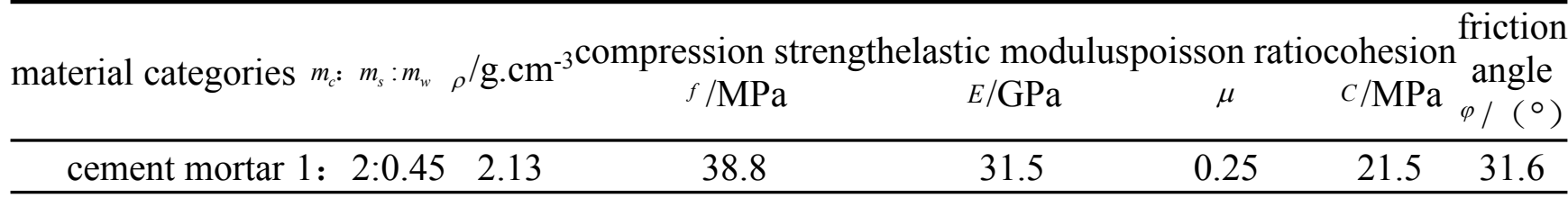

\section{Dynamic Impact Test Program}

As a standard test tool for rock dynamics recommended by the International Society for Rock Mechanics, the split Hopkinson pressure bar has been widely used in the dynamic mechanical parameter testing of rock, metal, concrete, mortar and other materials. Experimental study on the influence of joint number on dynamic properties of rock specimens in this paper was also done on Hopkinson pressure bar, and will be divided into three groups according to the number of joints (single-layer joints, double-layer joints and three-layer joints). 


\section{Dynamic Mechanical Analysis}

\section{Comparison of Measured Waveform}

Under the same (similar) impact load, the fluctuation curve of the specimen without joints is shown in Fig.5; Figure 6 is that the wave amplitude of approximately equal incident stress wave respectively were measured in the strain-time relationship between the waveform curve in different joints containing the number of specimens, found that:

(1) At similar impact velocities, the incident amplitudes are basically the same, and the incident waveforms are very similar. Due to the small impact velocity, the oscillations of the waveforms are obvious and the peak oscillation of the incident wave appears.

(2) The reflectivity of the simulated samples with different joint numbers is obviously different from that of the same incident stress wave. Also, the reflection waveform changes obviously. As the number of joints increases, the approximate " $\mathrm{V}$ " shape changes to "U" shape.

(3) After the stress wave passes through the specimen, the transmission amplitude $\varepsilon_{T}$ is less than the incident amplitude $\varepsilon_{I}$, and the transmission capacity of the joint specimen is obviously smaller than that of the intact specimen., the transmission ability is obviously weakened with the increase of the number of joints.

The experimental results show that under the same impact load, the attenuation of the stress wave is closely related to the number of joints when one-dimensional elastic stress waves pass through the specimens with different numbers of parallel and radial through-joints. When the number of joints is increased from 1 to 3 in a length of $100 \mathrm{~mm}$, the reflection waveform changes from an approximate "V" shape to a "U" shape, and the coverage area increases and the amplitude of the transmitted strain wave gradually decays.

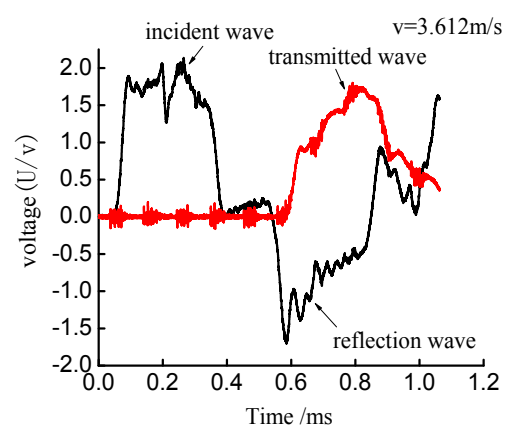

Fig.5 Wave curve of complete specimen
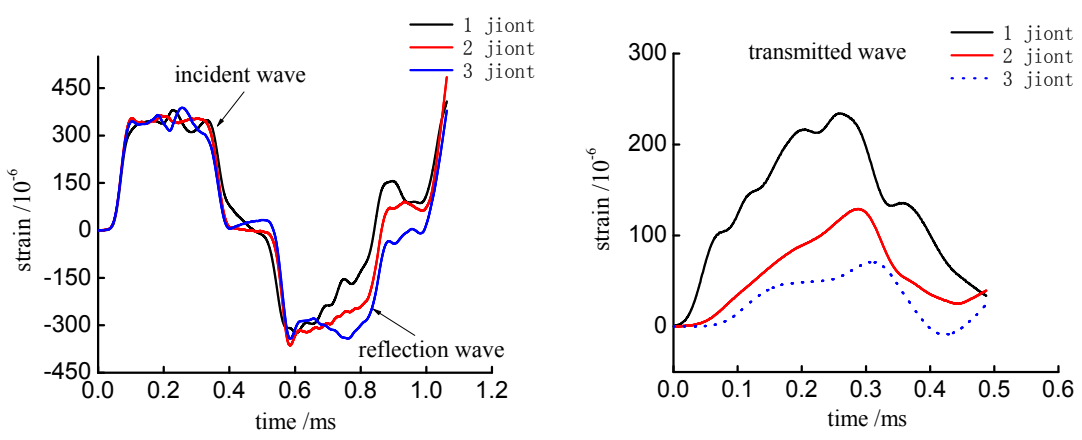

Fig.6 Strain-time relation of incident, transmitted and reflected pulses normal to specimens with different joint sets

\section{Energy Transfer and Dissipation Analysis}

The energy equation for incident, reflected and transmitted waves is as follows: 


$$
\begin{aligned}
& E_{I}=A_{0} \rho_{0} C_{0}^{3} \int_{0}^{t} \varepsilon_{I}^{2}\left(t_{1}\right) d t_{1} \\
& E_{R}=A_{0} \rho_{0} C_{0}^{3} \int_{0}^{t} \varepsilon_{R}^{2}\left(t_{1}\right) d t_{1} \\
& E_{T}=A_{0} \rho_{0} C_{0}^{3} \int_{0}^{t} \varepsilon_{T}^{2}\left(t_{1}\right) d t_{1} \\
& E_{D}=E_{I}-E_{R}-E_{T}
\end{aligned}
$$

Among them: $E_{I} 、 E_{R} 、 E_{T} 、 E_{D}$ are respectively incident energy, reflected wave energy, transmitted wave energy and dissipated energy; $A_{0} 、 \rho_{0} 、 C_{0}$ were respectively the cross-sectional area of the entrance and transmission rods, the material density and the elastic longitudinal wave velocity; $\varepsilon_{I}\left(t_{1}\right) 、 \varepsilon_{R}\left(t_{1}\right) 、 \varepsilon_{T}\left(t_{1}\right)$ were the strain history of incident, reflected and transmitted waves.

Calculating and averaging the ratios of multiple sets of reflected energy, transmitted energy, and dissipated energy, the results were showed in Table 2. In Table 2, group $\mathrm{M}$, group $\mathrm{N}$ and group $\mathrm{T}$ were mortar specimens designed as one, two and three horizontal joints respectively, in the meanwhile, under the effect of similar impact velocity, the mean value of the ratio of reflection

\begin{tabular}{|c|c|c|c|c|c|c|c|c|}
\hline \multirow[b]{2}{*}{$\begin{array}{l}\text { set of } \\
\text { joints }\end{array}$} & \multirow[b]{2}{*}{$\begin{array}{l}\text { serial } \\
\text { number }\end{array}$} & \multirow[b]{2}{*}{$E_{I} / \mathbf{J}$} & \multicolumn{2}{|c|}{$E_{R} / E_{I}$} & \multicolumn{2}{|c|}{$E_{T} / E_{I}$} & \multicolumn{2}{|c|}{$E_{D} / E_{I}$} \\
\hline & & & $\begin{array}{l}\text { experiment } \\
\text { value } / \%\end{array}$ & $\begin{array}{c}\text { average } \\
\text { value } / \%\end{array}$ & $\begin{array}{l}\text { experiment } \\
\text { value } / \%\end{array}$ & $\begin{array}{c}\text { average } \\
\text { value } / \%\end{array}$ & $\begin{array}{l}\text { experiment } \\
\text { value } / \%\end{array}$ & $\begin{array}{c}\text { average } \\
\text { value } / \%\end{array}$ \\
\hline \multirow{4}{*}{1} & M3 & 69.33 & 51.32 & \multirow{4}{*}{49.89} & 30.36 & \multirow{4}{*}{31.41} & 18.11 & \multirow{4}{*}{18.50} \\
\hline & M5 & 76.98 & 48.21 & & 31.29 & & 19.86 & \\
\hline & M11 & 78.66 & 49.21 & & 32.38 & & 17.10 & \\
\hline & M12 & 75.21 & 49.34 & & 31.51 & & 18.94 & \\
\hline \multirow{3}{*}{2} & N1 & 76.72 & 60.83 & \multirow{3}{*}{63.14} & 22.78 & \multirow{3}{*}{21.97} & 16.45 & \multirow{3}{*}{16.52} \\
\hline & $\mathrm{N} 2$ & 75.36 & 62.01 & & 21.16 & & 16.79 & \\
\hline & N7 & 71.63 & 61.70 & & 21.97 & & 16.43 & \\
\hline \multirow{5}{*}{3} & $\mathrm{~T} 1$ & 72.92 & 78.41 & \multirow{5}{*}{80.46} & 5.84 & \multirow{5}{*}{5.18} & 18.65 & \multirow{5}{*}{14.36} \\
\hline & $\mathrm{T} 2$ & 65.22 & 79.09 & & 5.28 & & 14.71 & \\
\hline & $\mathrm{T} 3$ & 74.05 & 80.88 & & 5.13 & & 13.28 & \\
\hline & $\mathrm{T} 5$ & 71.17 & 81.28 & & 5.83 & & 11.76 & \\
\hline & T6 & 66.44 & 81.15 & & 5.76 & & 13.64 & \\
\hline
\end{tabular}
energy, transmission energy and dissipation energy in the process of stress wave transmission varied with the number of joints were showed in Fig.7, we can get:

Tab. 2 Statistics of energy transfer ratio of specimens with different joint sets

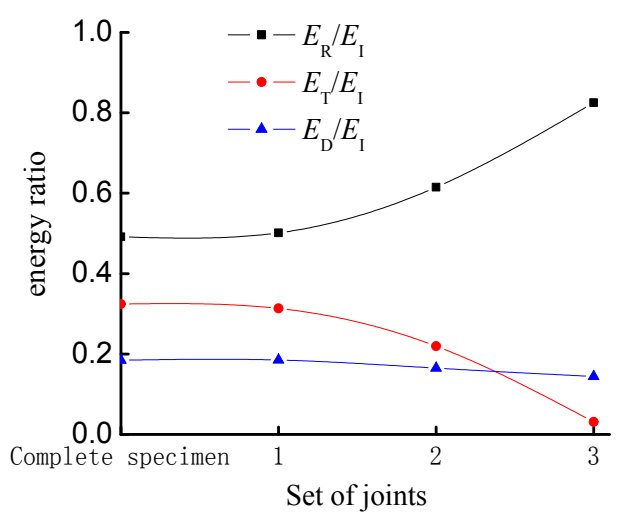

Fig. 7 Relationship of reflection, transmission and dissipation energy ratio with joint sets 
(1) The reflection, transmission and dissipation energy of a single horizontal joint specimen were equal to that of the basic and complete specimens.

(2) When the number of joints increased from 1 to 3 , reflective energy ratio increased gradually, from $50.09 \%$ to $82.46 \%$. The analysis showed that with the increase of the number of joints, the test pieces were cut into several sub-blocks, and after a certain sub-block has the initial crack, it continued to expand. Next, the expanding path also became short due to the increase of the number of joints. Finally, after the crack passed through, the sample breaks down and the strength begins to decrease; The stress wave lacked the transmissive medium and returned along the original path, causing the reflected energy ratio to rise, and the transmission energy ratio $E_{T} / E_{I}$ started to decreased, meanwhile, when the number of joints is $3, E_{T} / E_{I}$ ratio has dropped to a very low level of $3.18 \%$. In addition, the existence of joint fissures hindered the transmission of stress waves.

(3) From the energy dissipation ratio point of view, $E_{D} / E_{I}$ was not affected by the number of joints, but slightly reduced from $18.5 \%$ to $14.36 \%$.

\section{Strength Characteristics and Damage Morphology Analysis}

(1) Stress-strain Curve Analysis

The impact test of similar speed on several specimens with one, two and three joints respectively was carried out., and the experimental data were processed by three-wave method to get the stress-strain relations of the specimens with different joint numbers, as shown in Fig.8. The letter " $n$ " represented the number of parallel joints.

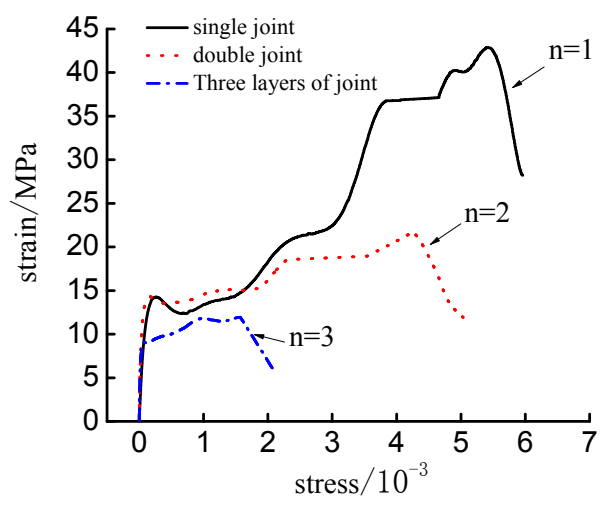

Fig. 8 Stress-strain curves of jointed specimens with different joint sets

From the relation curve of $\sigma-\varepsilon$, the peak intensity decreased obviously with the increase of the number of joints; The initial coincidence of stress-strain curves showed that the dynamic elastic moduli of the three kinds of joint specimens were almost equal, which showed that the number of closed parallel joints did not affect the initial dynamic elastic modulus of the specimens under the impact loading; After the elastic deformation stage, the curves of the three specimens fluctuated before the stress reached the peak. This was due to the fact that the crack propagates through the joint and affected the propagation of the stress wave in the axial direction, resulting in uneven stress in the specimen. In addition, with the increase of the number of joints, the strength of specimen decreased obviously, and the earlier the damage occured, the slope of curve decreased obviously. Thus, the number of joints not only affected the stress distribution and dynamic peak strength within the specimen, but also changed the stress failure process of the specimen under dynamic impact.

(2) Peak Intensity

Under similar speed impact conditions, the peak intensities of intact specimens and specimens 
with different joints vary with the number of joints, as shown in Fig.9. Obviously, for a 100mm long specimen, the peak intensity decreased approximately linearly with the increase of the number of parallel penetrating joints in the specimen itself; The dynamic compressive strength of the intact specimen was the largest, about 54.6 MPa. and the peak strength was reduced to $44.32 \mathrm{MPa}$ even for specimens with only one joint. It could be seen that with the increase of parallel joints, the maximum stress required to damage the specimen decreases, and the dynamic compressive strength of jointed rock mass was negatively correlated with the number of joints.

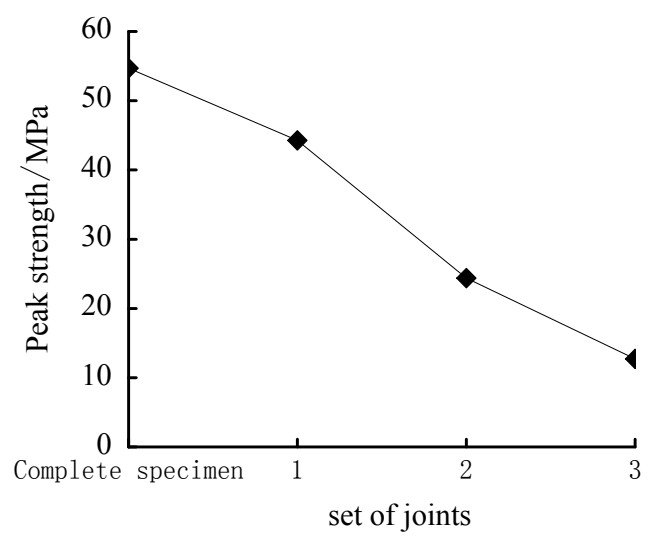

Fig. 9 Change law of the peak stress with joint sets

(3) Destroy The Form

From Fig. 10, the damage patterns of specimens with different joint numbers under the same or similar impact speed were mainly tensile failure under compressive stress. The single joint specimen was only an axial splitting failure of the specimen between the stress incident end and the joint surface, as shown in Figure 10 (a); The specimens with two parallel joints showed some fracturing damage on both sides of the joints, mainly along the direction of compressive stress, as shown in Fig. 10 (b); When the joint number $\mathrm{n}=3$, the specimen was severely damaged, and the main body was split into two halves in the axial direction with smaller fragments, as shown in Fig. 10 (c).

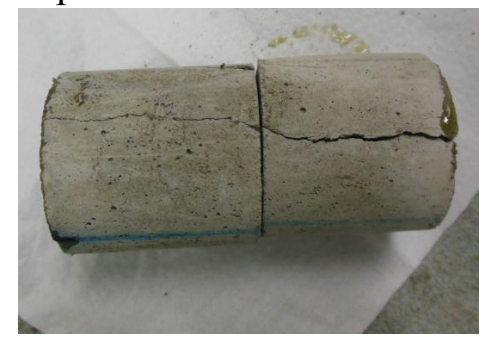

(a) $\mathrm{n}=1, \mathrm{v}=4.4 \mathrm{~m} / \mathrm{s}$

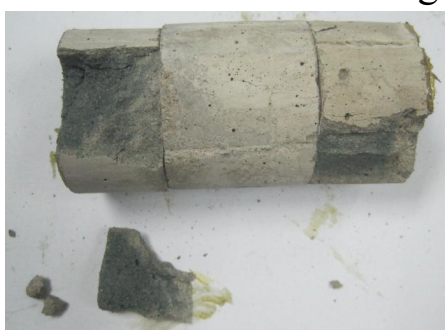

(b) $\mathrm{n}=2, \mathrm{v}=4.3 \mathrm{~m} / \mathrm{s}$

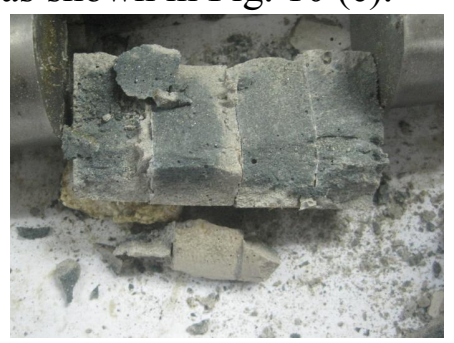

(c) $\mathrm{n}=3, \mathrm{v}=4.5 \mathrm{~m} / \mathrm{s}$

Fig. 10 Damage form of specimens with different joint sets

\section{Conclusion}

The reflection, transmission, and dissipation energy of a single horizontal joint specimen were substantially equal to a complete specimen. With the increase of parallel nodules, the integrity of the specimen was reduced and the damage was more serious. The transmission energy decayed gradually with the increase of the joint plane, and the failure stress of the specimen also decreased. Also, The dynamic compressive strength of the joint specimen was negatively correlated with the number of joints.

In this paper, the energy transfer law, dynamic strength characteristics and failure modes of the 
layered mortar under impact load were analyzed. Based on the experimental method, similar studies could be carried out on the complex structural materials in the project, and the experimental results were used to ensure the quality and safety of the project.

\section{Acknowledgments}

This work was financially supported by Project for Young Scientists Fund of Yunnan Science and Technology Department (2016FD029) and Scientific Research Fund Project of Yunnan Education Department (2016ZZX108). The corresponding author is YANG Yang.

\section{References}

[1] Hongyan LIU, Zhengding DENG, Xinsheng WANG, et al. Similar material test study of dynamic failure of jointed rock mass with SHPB[J]. Rock and Soil Mechanics, 2014, 35(3): 659-665.

[2] Liu Hongyan. Reply to discussion on a dynamic damage constitutive model for rock mass with non-persistent joints under uniaxial compression[J]. Chinese Journal of Geotechnical Engineering, 2016, 38(10): 1931-1932.

[3] Liu Hongyan, Su T. M. A dynamic damage constitutive model for a rock mass with non-persistent joints under uniaxial compression[J]. MECHANICS RESEARCH COMMUNICATIONS, 2016, 77(10): 12-20.

[4] Yang YANG, Renshu YANG, Jianguo WANG. Simulation material experiment on dynamic mechanical properties of jointed rock affected by joint thickness[J]. Journal of China University of Mining and Technology, 2016, 45(2): 211-216, 309.

[5] Renshu YANG, Maoyuan WANG, Yang YANG, et al. Simulation material experiment on the dynamic mechanical properties of jointed rock affected by joint-filling material[J]. 2016, 35(12): $125-131$.

[6] Xianglong Li, Jianguo Wang, Zhiyu Zhang, et al. Experimental study for effects of strain rates and joint angles on dynamic responses of simulated rock materials[J]. Explosion and Shock Waves, 2016, 36(4): 483-490.

[7] Xingping LI, Qian DONG, Tingting LIU, et al. Model test on propagation of blasting stress wave in jointed rock mass under different in-situ stresses

[J]. Chinese Journal of Rock Mechanics and Engineering, 2016, 35(11): 2188-2196.

[8] Pu YUAN, Qin-yong MA, Hai-dong ZHANG. SHPB tests for light weight foam concrete[J]. Journal of Vibration and Shock, 2014, 33(17): 116-119.

[9] Chai S B, Li Jianchun., Zhang Q B, et al. Stress Wave Propagation Across a Rock Mass with Two Non-parallel Joints[J]. ROCK MECHANICS AND ROCK ENGINEERING, 2016, 49(10): 4023-4032.

[10] Tingting LIU, Jianchun LI, Haibo LI, et al. Energy Analysis of Stress Wave Propagation across Parallel Nonlinear Joints[J]. Chinese Journal of Rock Mechanics and Engineering, 2013, 32(8): 1610-1617.

[11] Jin YU, Boxue SONG, Qihu QIAN. Study of Propagation of P-Waves in Dual Nonlinear Elastic Rock Medium with One Set of Joints[J]. Chinese Journal of Rock Mechanics and Engineering, 2012, 31(12): 2400-2411. 